\title{
NON-LINEAR ANALYSIS TO IMPROVE PUNCHING SHEAR STRENGTH IN FLAT SLAB USING Z-SHAPE SHEAR REINFORCEMENT
}

\author{
Abdulnasser Mohammed Abbas ${ }^{1}$, Haleem K. Hussain ${ }^{2}$, Ahmed Sagban Saadoon ${ }^{3}$ \\ 1,2,3 Department of Civil Engineering, College of Engineering, University of Basrah
}

\section{ARTICLE INFO}

Received:07/08/2019

Accepted: 20/10/2019

\section{Keywords}

Flat slab, punching shear, shear reinforcement, $\mathrm{FE}$ analysis, ABAQUS

\begin{abstract}
Currently, flat slabs become one of the widely used structures due to its architectural benefits such as uncomplicated formwork, flexibility and minimum construction time. However, these structures are relatively weak to resist the punching shear due to a considerable lowering in stiffness induced from the development of cracks that resulting from axial and seismic loads. Moreover, the punching failure is considered a brittle failure caused by the transferring of unbalanced moments and shear forces between the structural members. Unfortunately, this may cause a catastrophic collapse, especially in the region of the slab-column. Therefore, many experimental and theoretical studies were done to improve the punching strength of the flat slab. In the current work; a finite element three-dimensional non-linear analysis has simulated by ABAQUS tool to investigate the structural behaviour of flat slab. Two specimens have considered, the first is a flat slab reinforced by ordinary steel reinforcement. While in the second one, a Z-shape shear rebar improvement has been added to the slab-column connection. The proposed model has reflected a reasonable enhancement to the flat slab. The analysis considers different parameters such as punching shear forces, deformations, and stresses of Von-Mises. The outcomes indicate that punching shear strength is increased by approximately $11.1 \%$, and the deflections are decreased by $77.3 \%$ when the Z-shape reinforcement is used. In the meantime, stress concentrations were reduced and move from the slab-column connection.
\end{abstract}




\section{Introduction}

Flat slab system is widely employed in office and parking buildings for many reasons such as lower cost of the formwork and constructed in a fast and simple manner. Actually; this kind of structures mainly consists of a concrete slab which is propped by concrete columns with no need of beams [1]. In spite of these advantages, generally, the design of a flat slab is ruled by localized influences such as failure due to punching shear and huge deflections at mid-span. Moreover, there are uncertainties of the structural behavior at the slab-column connection zone [2].

Punching shear is a brittle failure, which arises when the compression inclined area is incapable to bear any increments of the load [3]. The failure of punching shear can be defined as a diagonal crack growth, which is beginning from the column face and closing at the slab tension surface, and hence, may cause a conic dislocation body from the slab [4].

Numerous studies have been done to improve the structural behavior of the flat slab, especially in the slab-column connection zone to guarantee adequate resistance of the structure. Various types of shear connection have used in these investigations such as shear reinforcement [5,6], stud rail [7], steel fibre [8], and post-tensioned system [9].

A prestressing technique was used by Clement et al. $[10,11]$ and Fernandez et al. [12] to increase the slab-column connection strength. While Pilakoutas and Li [13] used high ductility steel strips to enhance the shear band at the critical region. Subedi and Baglin [14] developed a system named (NUUL), which consisted of $U$ bars and a plate of steel, by inserting a steel sheet to the slab to enhance the column effective head area, and then, increasing the strength of punching of the slab-column link.

Fernandez and Muttoni [15] studied the punching behaviour of concrete slabs that reinforced by transverse rebar using the theory of shear critical crack. They found that the concrete contribution to the flat slab punching strength is not stable, and it is reducing at a relatively large slab rotation.

Maya [16] construct a mechanical model to estimate the punching shear strength and the structural behaviour of flat slabs that reinforced by steel fibres [16]. A comparison has done between the presented model with at least 140 connections of slab-column. They find that the presented model reveals a reasonably good agreement with the gained results.

The current study deal with two types of flat slabs, the first is reinforced by ordinary steel rebar (SOR), while the second is enhanced by using Zshape shear rebar at the zone adjacent to the column face (SZR). The finite element three-dimensional technique is used to simulate the two specimens by using ABAQUS tool.

\section{The Orientation of Research}

As mentioned previously, there are various manners to enhance the punching shear strength of the flat slab, one of these types is the headed shear stud. Codes such as ACI and Euro Code 2 recommend three configurations of the shear studs at the slab-column connection zone [17], which are (a) Orthogonal pattern, (b) Radial patterns, and (c) Critical perimeter pattern, see Figure (1):

In the first pattern (orthogonal), the studs located in parallel with the edge of the column, to resist the progress of the crack in the orthogonal trend. In the next style, studs will arrange in radial lines, and hence, crack propagation will radially be prevented. The last pattern considered as a conjunction between radial and orthogonal patterns, which is used to resist the progress of the crack in both trends. In this paper, studs will be replaced by Z-shape rebar, which will be arranged in an orthogonal pattern. The essential aim of the current study is to discover the Z-shape shear reinforcement effect on the flat slab, and what benefits that may be obtained from using such type of reinforcement.

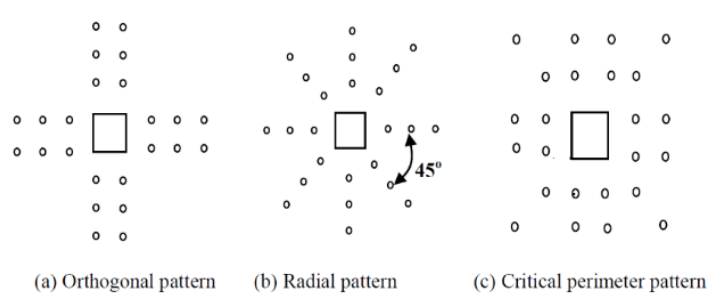

Figure (1): Configurations of shear studs ${ }^{[17]}$

\section{Finite Element Modelling of Flat Slab}

The model that considered in this study consists of a square flat slab (1500 mm x $1500 \mathrm{~mm})$ with a thickness of $150 \mathrm{~mm}$, connected together with a central column $(200 \mathrm{~mm} \times 200 \mathrm{~mm})$. A threedimensional model has structured using a finite element (FE) technique, and stimulated by an ABAQUS environment as shown in Figure (2). To form an adequate mesh, it is preferable to divide both the slab and column into fine elements, therefore, the problem will be subdivided into smaller ones. Hence, elements of eight-node hexahedral will be provided by meshing. Each node is defined by three DOF for displacement in $\mathrm{x}, \mathrm{y}$ and $\mathrm{z}$ directions. Then, matrices of element connectivity, nodal coordinate, and stiffness matrix are formed [18].

To simulate the concrete; a C3F8R brick element has been used. It is a three-dimensional (solid) element having eight nodes used in the distorted aspect calculations. While the whole reinforcement bars are simulated by a T3D2 truss normal plasticity element. This element formulates the steel rebar with two DOF for each node [19]. 


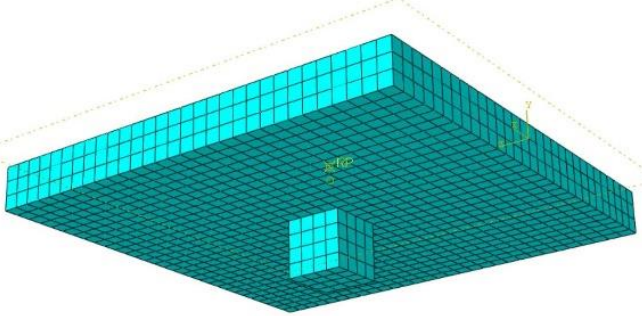

Figure (2): Meshing of flat slab

\subsection{Non-Linear Analysis:}

A non-linear stress-strain relationship for concrete was considered in this study. To implement such type of analysis, an incremental pattern of the Newton-Raphson method will apply. Therefore, the externally loaded force will divide into a number of tiny loads that increased gradually to the applied one; these increments are usually specified by the user. Then, an iteration process for each load increase will begin to keep the residual force magnitude very small and to achieve the required convergence, and the matrix of tangent stiffness are simultaneously calculated. In the next increment; the new tangent stiffness matrix is updated using the last step [18], see Figure (3).

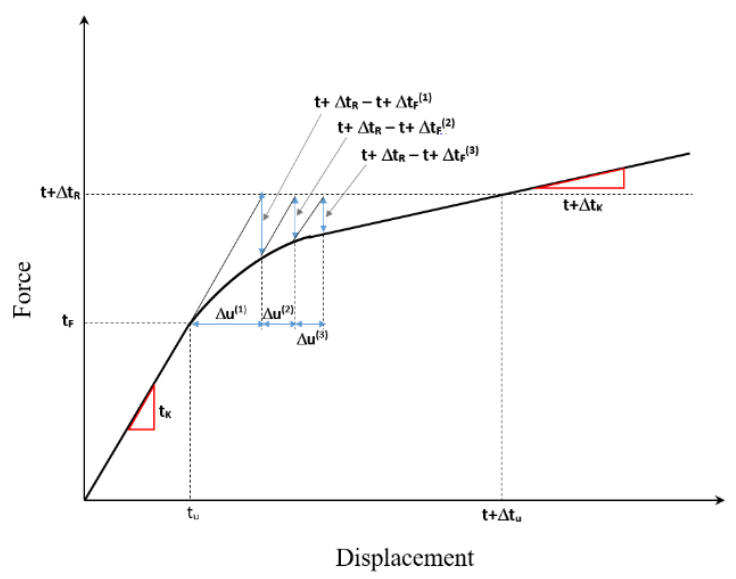

Figure (3): Newton-Raphson Convergence [18]

\subsection{Damaged Plasticity Pattern:}

This pattern uses two types of inelastic models consisting of damage and plasticity. Both of them depend on the effective stress principle that acting on the undamaged material structure and including perpetual strains when the ultimate limit is attained. In ABAQUS, the damage plasticity pattern involves the influence of irreversible damage and mild impound pressure, concentrating on the mechanism of failure for semi-brittle materials such as concrete [20], the damage plasticity parameters used in this study are listed in Table (1). In the concrete flat slab, the cone of the punching shear becomes visible at the ultimate load due to abrupt cracks opening in concrete. The pattern of damage plasticity in concrete presumes that the cracking will initiate in the positive case of ultimate essential plastic strain.
The specifications of the materials that used in this study are shown in Table (2).

Table (1): Parameters of concrete damage plasticity

\begin{tabular}{cc}
\hline Item & Value \\
\hline Dilation Angle & 30 \\
Eccentricity & 0.1 \\
$\mathrm{~K}$ & 0.6667 \\
Viscosity Parameter & 0.0001 \\
$f \mathrm{~b}_{0} / f \mathrm{c}_{\text {。 }}$ & 1.16 \\
\hline
\end{tabular}

Table (2): Materials Specifications

\begin{tabular}{cccc}
\hline Material & $\begin{array}{c}\text { Poisson's } \\
\text { Ratio }\end{array}$ & $\begin{array}{c}\text { Density } \\
\mathrm{Kg}^{3} \mathbf{m}^{3}\end{array}$ & $\begin{array}{c}\text { Young } \\
\text { Modulus } \\
\text { MPa }\end{array}$ \\
\hline $\begin{array}{c}\text { Concrete } \\
\text { Steel }\end{array}$ & $\mathbf{0 . 2 0}$ & $\mathbf{2 4 0 0}$ & $\mathbf{2 5 . 7 5 4}$ \\
Rebar & & $\mathbf{7 8 0 0}$ & $\mathbf{2 1 0}$ \\
\hline
\end{tabular}

\section{Model Verification}

Nasr et al. [21] investigate seven flat slabs with dimensions of $1700 \mathrm{~mm}$ (length) x $1700 \mathrm{~mm}$ (width) and $160 \mathrm{~mm}$ (depth) connected with an interior square column of length $20 \mathrm{~mm}$ and height of 250 $\mathrm{mm}$. The seven specimens were reinforced with two layers of rebar (the top mesh: $14 \phi 10$ and the bottom mesh: $14 \phi 16)$. Moreover, strips made of steel with a width of $25 \mathrm{~mm}$ and a thickness of $1.5 \mathrm{~mm}$ were undulated in the flat slab with different ways to study the punching shear resistance.

In the present numerical investigation, the control specimen which is used in the above experimental work is simulated in ABAQUS to verify the 3-D finite element model. Figure (4) shows the load-deflection curve for both the numerical and the experimental samples. It can be seen that there is a slight deference between the numerical and the experimental sample, and the average difference for the last four readings is approximately $0.94 \%$. As compared with the experimental control sample, the ultimate load is increased for the FE model by $3 \%$. This indicates that the outcomes gained from the 3-D finite element model reasonably agree with the experimental outcomes.

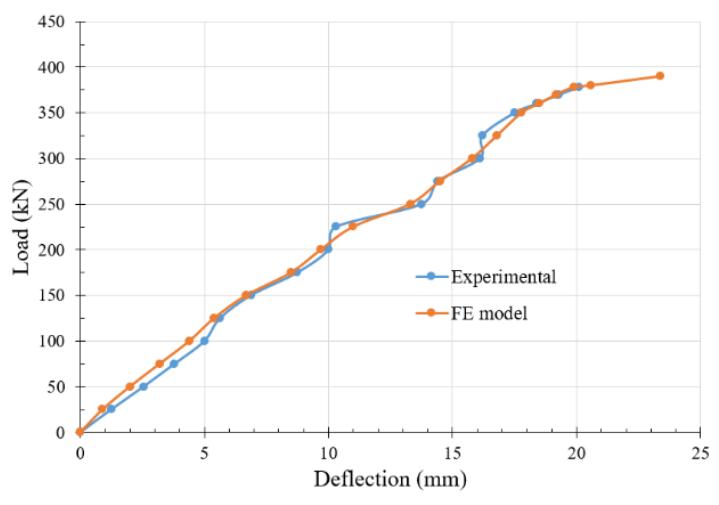

Figure (4): Load deflection curve to verify the 


\section{Results and Discussion \\ 3-D FE model}

In the current study, two models of the flat slab are tested using a three-dimensional FE analysis. The first is a flat slab with an ordinary reinforcement (SOR), while in the other one, an enhancement for punching shear is considered by adding Z-shape shear reinforcement (SZR). An orthogonal type of reinforcement has provided considering the distance from the column face which varying from $(d / 2)$ to (2d), see Figure (5).

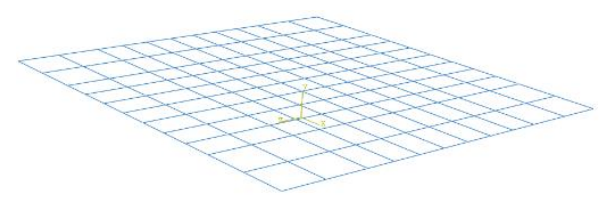

A

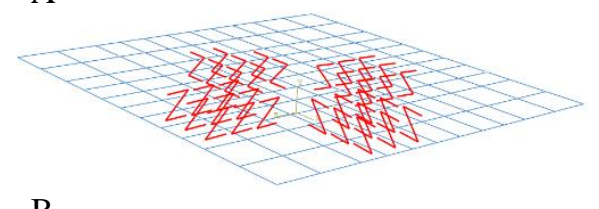

B

Figure (5): Simulation of rebar- A: Ordinary reinforcement, B: Ordinary reinforcement with Z-shape shear reinforcement

Figure (6) shows the contour distribution of the vertical deflection for the proposed FE models. It can see from this figure that the slab with zero shear reinforcement suffers from an excessive deflection; in contrast, the deflections for that slab with Z-shape shear reinforcement are relatively adequate.

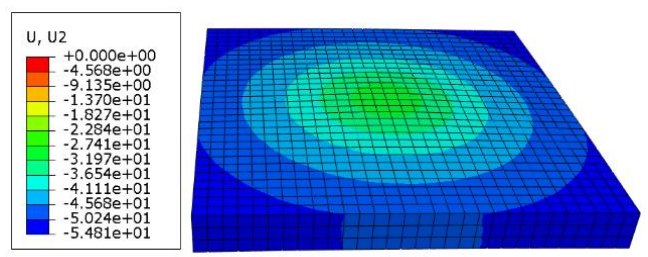

\section{A - SOR}
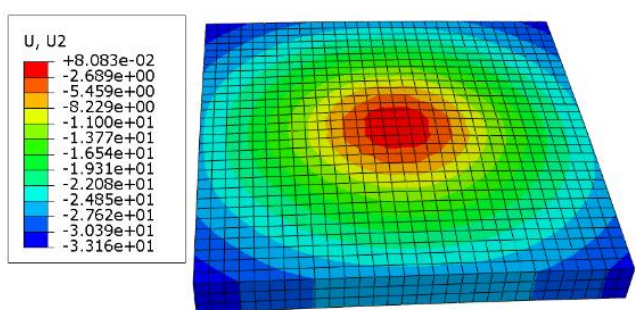

\section{B-SZR}

Figure (6): Deflection contour distribution

Figure (7) exhibited the load-deflection relation for both of the FE models. When the load is $100 \mathrm{kN}$, the vertical deflection in the SOR slab is $2.13 \mathrm{~mm}$, while for the SZR slab, the deflection is $0.53 \mathrm{~mm}$, with a difference between the two values of (1.6 $\mathrm{mm})$. However, when the load is $250 \mathrm{kN}$, the difference will become $7.58 \mathrm{~mm}(14.78 \mathrm{~mm}$ for the OSR and $7.20 \mathrm{~mm}$ for SZR slab). Furthermore, at a load equal to $405 \mathrm{kN}$, the variance becomes 30.99 $\mathrm{mm}$. In the meantime, the ultimate load for the flat slab with no Z-shape reinforcement is $405 \mathrm{kN}$, while the SZR slab fails at $450 \mathrm{kN}$ with an increase of ultimate load by $11.1 \%$. The gained results indicate the importance of adding the Z-reinforcement by decreasing the vertical deflection and increasing the ultimate load.

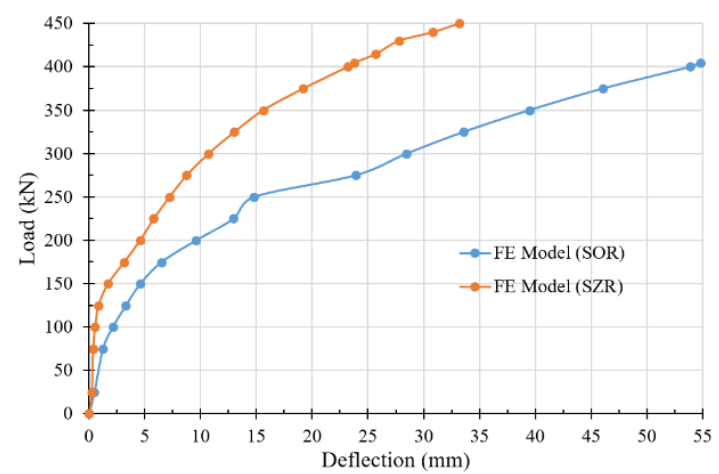

Figure (7): Load vs deflection curve for the two tested slabs

Figure (8) shows the distribution of the vertical deflection along the $\mathrm{x}$-direction. The vertical deflection is decreased for the (SZR) slab by 57.92 $\%$ (at $150 \mathrm{~mm}$ ) to $99.5 \%$ (at the slab center) with an average of $77.33 \%$. This minimizing in deflection is caused by an introducing of the Z-shape strengthen to the slab.

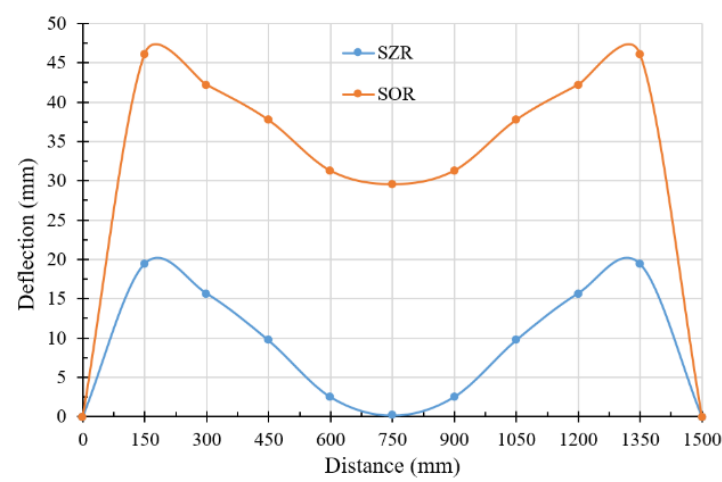

Figure (8): Load-deflection distribution along the $x$-axis

The Von Mises stresses are also considered for the taken two slabs, see Figures (9) and (10). The distribution of Von Mises stresses along the $\mathrm{x}$ direction of the slab is shown in Figure (9). It can be seen that the Von Mises stresses are much higher for the slab (SZR) slab especially at the slab center and near the column faces. Figure (10) exhibited the counter distribution of Von-Mises. 


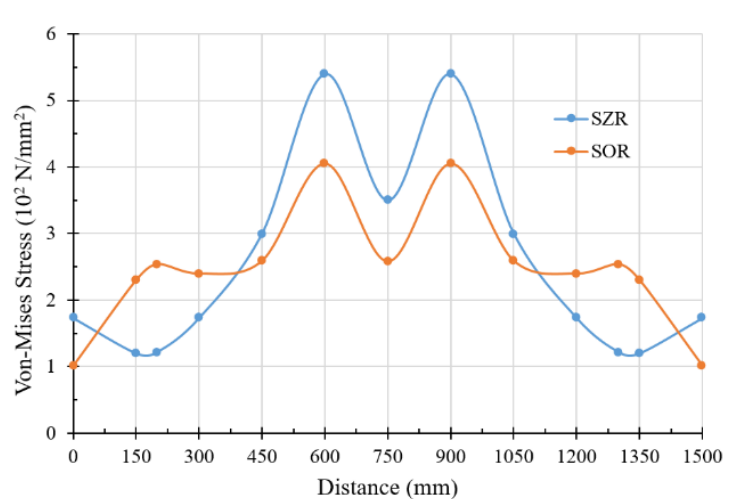

Figure (9): Von Mises stress distribution along the $x$-direction of the slab

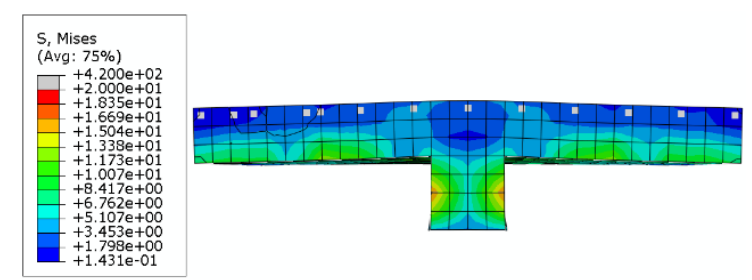

A- SOR

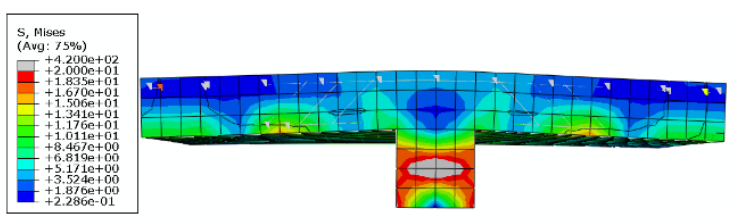

B-SZR

\section{Figure (10): Von-Mises counter distribution}

Figure (11) shows the counter distribution of the cracks for proposed FE models. It is seen that the cracks are concentrated adjacent to the slab-column connection, for both of the two models. However, the concentration of the crack decreased, for the (SZR) slab by $72.6 \%$ due to the Z-shape (rebar) enhancement for the punching shear strength.

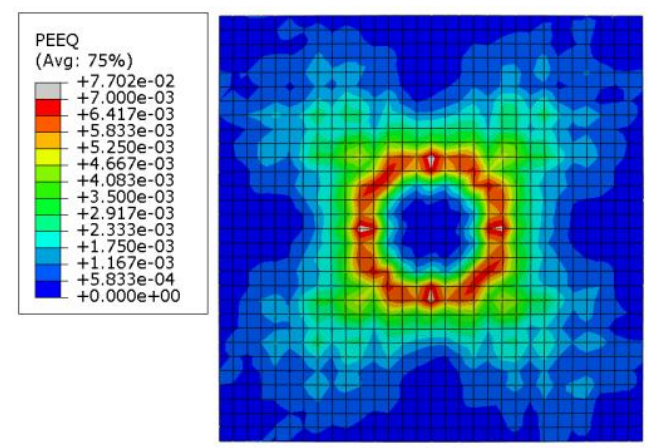

A- SOR

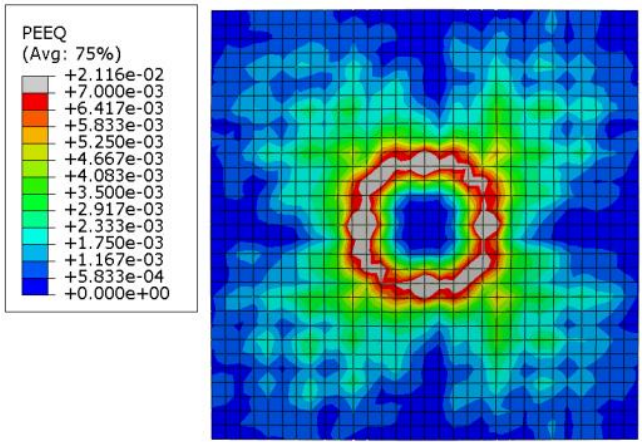

B-SZR

Figure (11): Counter distribution for crack path

Finally, there are many kinds of improvement for the punching shear strength in the flat slabs. However, some of these methods need careful attention during the fabrication and installation, such as headed studs, stirrups, swimmer bars... etc. [22]. On the other hand, the manufacturing and installation of the Z-shape reinforcement, which has utilized in this study, is quite simple and cost a minimum budget particularly, when utilizing the available waste rebar in the construction site.

\section{Conclusions}

In the current study, a nonlinear FE analysis is done for two types of slab SOR and SZR. The first slab is designed using ordinary reinforcement, but without Z-shape shear rebar. While the second one, an enhancement for the shear is involved in the region adjacent to the column face. A comparison is done with experimental work to verify the used FE models. Results show that there is a reasonable agreement between the experimental and the proposed FE models. From the analysis outcomes that gained from the two FE models, it can be concluded that:

1. The manufacturing of the Z-shape reinforcement is simple and more economical as compared with the other types of shear reinforcement such as studs or steel plates, especially when using the available (waste rebar) in the construction site.

2. The punching force is increased due to involving the Z-shape shear reinforcement by $11.1 \%$.

3. The difference in defection between SOR and SZR is $1.6 \mathrm{~mm}$ at $100 \mathrm{kN}$, while the difference will become $30.99 \mathrm{~mm}$ at $405 \mathrm{kN}$.

4. The deflection is generally decreased by an average amount of $77.33 \%$ as a result of using Z-shape shear rebar.

5. The stresses concertation is decreased and moving away from the slab-column connection zone due to the shear enhancement. 


\section{References}

1- Harshal Deshpande, Radhika Joshi, Prashant Bangar, "Design Considerations for Reinforced Concrete Flat Slab Floor System", International Journal of Scientific \& Engineering Research, Volume 5, Issue 12, December-2014.

2- Dan V. Bompa, Traian Onet, "Punching shear strength of RC flat slabs at interior connections to columns", Magazine of Concrete Research, 68(1), 2016, 24-42.

3- Hallgren M, "Punching Shear Capacity of Reinforced High-Strength Slabs", Ph.D. thesis, KTH Stockholm, Stockholm, Sweden, TRITBKN, Bulletin 23, 1996.

4- Regan PE, "Symmetric punching of reinforced concrete slabs", Magazine of Concrete Research 38(136): 115-128, http://dx.doi.org/10.1680/macr.1986.38.136.1 $\underline{15}, 1986$.

5- Robertson, I. N., Kawai, T., Lee, J., and Enomoto, B., "Cyclic Testing of Slab-Column Connections with Shear Reinforcement", ACI Structural Journal, 99(5), 2000, 605-613.

6- Park, T. W., "Inspection of Collapse Cause of Sempoong Department Store", Forensic Science International, 217(1-3), 2011, 119126.

7- Gunadi, R., Budiono, B., Imran, I., and Sofwan, A., "The Behavior of Slab-Column Connections with Modified Shear Reinforcement under Cyclic Load", Journal of Engineering and Technological Sciences ITB. 46(1), 2014, 17-36.

8- McHarg, P. J., Cook, W. D., Mitchell, D., and Yoon, Y. S., "Benefits of Concentrated Slab Reinforcement and Steel Fibers on Performance of Slab-Column Connections", ACI Structural Journal. 97(2), 2000, 225-235.

9- Kang, T. H. K., Wallace, J. W., and Elwood, K. J., "Dynamic Tests and Modelling of RC and PT Slab-Column Connections", Proceedings of the 8th U.S. National Conference on Earthquake Engineering. San Francisco, California, 2006.

10-T. Cl'ement, A. P. Ramos, M. F. Ruiz, and A. Muttoni, "Design for punching of prestressed concrete slabs," Structural Concrete, vol. 14, no. 2, 2013, pp. 157-167.

11-T. Cl'ement, A. Pinho Ramos, M. Fern'andez Ruiz, and A. Muttoni, "Influence of prestressing on the punching strength of posttensioned slabs", Engineering Structures, Vol. 72, 2014, pp. 56-69.

12-M. Fern'́andez Ruiz, Y. Mirzaei, and A.Muttoni, "Post-punching behavior of flat slabs", ACI Structural Journal, vol. 110, no. 5, 2013, pp. 801-811.

13-K. Pilakoutas and X. Li, "Alternative shear reinforcement for reinforced concrete flat slabs", Journal of Structural Engineering, vol. 129, no. 9, 2003, pp. 1164-1172.

14-N. K. Subedi and P. S. Baglin, "Design of slabcolumn junctions in flat slabs", Proceedings of the Institution of Civil Engineers: Structures and Buildings, vol. 156, no. 3, 2003, pp. 319331.

15-Fernandez Ruiz M., Muttoni A., “Applications of the Critical Shear Crack theory to punching of R/C Slabs with transverse reinforcement", ACI Structural Journal, Vol. 10, 6 No. 4. 2009, pp. 485-495.

16-Maya Duque, Fernandez Ruiz, M. Muttoni and Foster S. J., "Punching Shear Strength of Steel Fiber Reinforced Concrete Slabs", Engineering Structures, Vol. 40, UK 2012, pp.93-94.

17-T.S. Viswanathan, G. Mohan Ganesh2\& A.S. Santhi, "Investigation of Shear Stud Performance in Flat Plate Using Finite Element Analysis", J. Eng. Technol. Sci., Vol. 46, No. 3, 2014, 328-341.

18-Saurabh AGRAHARI, Pradeep Kumar RAMANCHARLA, "Understanding The Behavior of Flat Slab by Linear and Nonlinear Finite Element Analysis", New Technologies for Urban Safety of Mega Cities in Asia, November 2017, Sendai, Japan.

19-Asdam Tambusaya, Priyo Suproboa, Faimuna, Arwin Amiruddinb, "Finite Element Analysis on the Behavior of Slab-Column Connections using PVA-ECC Material", Jurnal Teknologi (Sciences \& Engineering) 79:5, 2017, 23-32.

20-Georgewill V.A., Ngekpe B.E., Akobo I.Z.S. and Jaja G.W.T., "Punching Shear Failure of Reinforced Concrete Flat Slab System- A Review", European Journal of Advances in Engineering and Technology, 6(2), 2019, 1016.

21-Nasr Z. Hassan, Mostafa A. Osman, Awad M. El-Hashimy, and Heba K. Tantawy, "Enhancement of punching shear strength of flat slabs using shear-band reinforcement", Housing and Building National Research Center, HBRC Journal, 2017.

22-Ahmed Sagban S., Abdulnasser Mohammed A., and Haleem K. Hussain, "A Review on Flat Slab Punching Shear Reinforcement”, accepted for publication in the Journal of University of Babylon, Engineering sciences, Vol. ( $Y$ V $)$, No. (r), 2019 . 